\title{
THE RELATION OF STATE AND LOCAL BOARDS OF HEALTH TO OUTBREAKS OF DIPHTHERIA.*
}

\author{
BY G. E. TYLER, M.D. \\ Of Denver, Col. ; Secretary of Colorado State Board of Health.
}

THE presence of one case of genuine diphtheria in a community is an occurrence of sufficient importance to demand the earnest attention of those responsible for the prevention of the unnecessary spread of disease; for a single mild case may mean many severe ones, and the death of not a few individuals. If Pasteur's now famous aphorism, "It is in the power of man to cause all parasitic diseases to disappear from the world," be true, there is need of greater ability in applying our present knowledge concerning this one. As diphtheria is a disease for which there exists a positive method of diagnosis and a specific treatment, Pasteur's prophecy ought to have a fair testing in its management. It is my purpose to attempt to set forth the methods to be used by health officials in their battle with this disease.

There should, at all times and in all places, be offered competent bacteriologic facilities free of charge to every citizen. The absolute uncertainty of clinical phenomena for mild or atypical cases has been repeatedly proved. The throat may present but the faintest hyperæmia, yet the culture may be positive. In well-marked cases the elinical appearances are sufficiently distinct to warrant a positive diagnosis without the aid of a bacteriologist, but it cannot be too strongly emphasized that the greatest skill in clinical work is not sufficient to detect mild eases of genuine diphtheria. Because of this fact no obstacle should be placed in the way of obtaining a prompt bacteriologic diagnosis. On the contrary, every facility should be offered the interested person, whether he be a physician or an anxious parent. Culture outfits in convenient form should be placed at accessible supply depots, each outfit being accompanied by plain printed instructions as to the method of use. In cities messengers should be provided to collect the outfits as soon as the cultures have been taken. Whenever requested, an officer of the local board of health should be sent to take the eulture. In small communities it is quite out of the question to maintain a bacteriologic laboratory. It then becomes the duty of the State Board of Health to supplement the work of the local board by

* Read before the Colorado State Medical Society, June, 1900. Reprinted from Phil. Med. Jour., January 5th, 1901. 
furnishing the necessary facilities. To accomplish this, the State Board of Health must have a competent bacteriologist, not appointed. for political reasons. It must also provide all incorporated towns which have no local laboratory with eulture outfits, and there must be prompt communication between the supply depots and the laboratory. The culture outfits should be as complete as possible, in order that the cost of sending them may be reduced to the minimum. The former regulations of the Post Office Department required a clumsy outfit which was poorly adapted to the work, and which required twelve cents postage every time it was mailed. Through the efforts of the Colorado State Board of Health, assisted by others interested, the regulations were so modified as to permit the use of a much smaller outfit. It was formerly the custom to treat these specimens as fourth-class mail, but the new order directs that they be treated as letter mail. This may mean a difference of twelve hours in the receipt of the specimens. Every State Board of Health should be granted sufficient funds to establish these supply depots. The State Board of Health of Colorado had such depots established in every county about September 1, 1900. The service of the laboratory is free of charge to every eitizen, and reports are made as promptly as possible. In every positive case immediate report will be made by telegraph. A like prompt report will be made in negative cases when requested. In sending specimens the name of the patient should be given as well as that of the person sending the specimen.

Physicians should take cultures in every case which looks at all suspicious. Much tact is required to secure the active participation of some in this movement, but the wise health officer will so protect the interests of the profession that all, except the few who are by habit opposed to everything, will see the advantage to be gained by frequent use of the laboratory.

Free antitoxin should be provided for all infeeted individuals who cannot afford to buy it. The early use of antitoxin is of such extreme importance to the successful management of diphtheria that physicians should be given to understand that whenever they have a case which demands it, antitoxin sufficient for the patient ean be had for the asking. As the State Board of Health has no funds for such purpose, local boards must supply this.

Every case of diphtheria should be reported to the health authorities, and a record of it be made by them. Physicians outside the large cities of Colorado do not seem to know that the law requires immediate report of all cases of contagious disease, but they have usially been willing to make such reports when 
informed of the law. The State Board of Health furnishes blanks for such reports free of charge, and is seeking to make complete and accurate record of all cases. The record made by the health authorities should show the exact location of the patient, the number and names of the rest of the family, and all others known to have been exposed. The local boards should make note of the milk, water, and ice supply, and, if there are children in the family, the school and Sunday-school should be recorded. The officers of such schools should have early notification of the existence of the disease; the public librarian should be notified in order to see whether any books are in the family, and care should be exercised to prevent the spread to other families by the milk-supply. For the protection of the public, every house in which diphtheria is present should be distinctly placarded. Some have questioned the necessity of the placard, but every person visiting a house has a right to know before he enters whether he will eneounter diphtheria by entering. If every infected house is placarded without favour to rich or poor, the community will appreciate the value and justice of the regulation. The regular notification of public schools and Sunday-school officers does much to edueate public sentiment. Furthermore, the record of such data often enables the intelligent health officer to trace the different cases to a common source.

The great value of keeping record of the milk-supply has been demonstrated many times.

The question of quarantine is important. Who shall be quarantined, and for how long? The patient must be quarantined until his throat is free from bacilli. This seldom oceurs under three weeks, and because people grow restive under repeated positive reports it is wise to fix the minimum period of quarantine at three weeks, and to take no secondary cultures during this time. The Colorado State Board of Health has adopted the following rule:

"In all cases where the bacteriologist reports the diphtheria bacilli present, the patient should be absolutely quarantined. A second culture should be taken twenty-one days after the first, and forwarded for examination. Quarantine must be maintained until the bacteriologist reports the throat free from diphtheria bacilli. No children from the family should be allowed to attend school until two weeks after the throat is free from the diphtheria bacilli."

The breadwinners need not be kept from their work, unless they be school teachers, or others who mingle much with children, but they should be cautioned to be little in the sick-room, or else to be careful to change their clothing and bathe with antiseptics before leaving the house. Before a nurse employed in a diphtheria case goes to another patient a culture from her throat should be 
examined, and her elothing should be disinfected. In fatal cases of diphtheria the funeral should be private, and under the supervision of a health officer.

Those exposed should be given immunizing doses of antitoxin, and this should be repeated in two weeks if exposure continues. With the present state of public opinion, it is not wise for health officers to insist upon immunization of the exposed, but they should do all in their power to encourage it. Some day the custom of immunization after exposure to diphtheria will be as common as vaccination after exposure to small-pox.

The State or local board of health should have circulars for public distribution, and one of these should be placed in the hands of the head of the family where the disease appears. The following is from a circular on this subject issued by the Colorado State Board of Health, it being identical with one previously issued by the Denver Bureau of Health:

"Diphtheria is a disease which manifests itself especially in the throat. It is so dangerous and so difficult of identification, that every sore throat should be regarded as suspicious, and the person suffering from it kept out of school until the throat has been examined by a competent person, and the nature of the sickness determined. The State Board of Health determines absolutely the existence or nonexistence of diphtheria by a bacteriologio examination of the secretion from the throat, and this examination is made at the request of any citizen without charge. Children from houses in which diphtheria has oceurred should not be allowed to resume school attendance until two weeks after a bacteriologic examination has shown the throat of the sick person to be free from diphtheria germs, as certified by the health authorities."

Toys with which the sick child has played should be destroyed or soaked in a strong antiseptic. Books should be burned, and all articles which will stand it should be separately boiled. The necessity for thorough fumigation is apparent. For disinfection of the room the Colorado State Board of Health recommends five pounds of sulphur to each 1,000 cubic feet of space, with exposure for twelve hours; or formaldehyde sprinkling, using five ounces of the 40 per cent. solution for each 1,000 cubic feet of space. The objection to the former is its corrosive action, and to the latter its poor penetration.

The constant use of the bacteriologic test, the prompt application of the serum treatment, complete isolation of infected individuals, immunization of all exposed, and thorough disinfection-these are the methods which, intelligently applied, will prove the truth of Pasteur's aphorism. 